\title{
Dynamic Effect of Capillary Pressure in Tight Gas Reservoir
}

\author{
Ailin Jia ${ }^{*}$ and Zhikai Lv
}

Research Institute of Petroleum Exploration \& Development of CNPC, Beijing 100083, China

\begin{abstract}
Standard theories for two-fluid flow in porous media assume capillary pressure to be in equilibrium. Numerical simulators often assume that equilibrium capillary pressure-saturation conditions are maintained as changes in fluid saturation are taking place. But recent theories indicate that capillary pressure is perhaps not only a function of saturation but also rate change, which is known as the dynamic effect. In order to investigate effects of the dynamic capillary pressure on fluid flow in tight gas reservoirs, standard theory and present novel pore-scale and Darcy-scale theoretical approaches that account for a dynamic capillary pressure were reviewed in this paper. A dynamic capillary pressure relationship was included in the mathematical and numerical schemes were proposed to simulate tight gas reservoir production, which allows one to identify previously unreported flow scenarios. The numerical schemes were also to modify the Gray and Hassanizadeh equation for infiltration to account for a capillary pressure that depends on the flow velocity. This study is of great benefit to finding out the flow law of tight gas reservoir and the subsequent work of exploitation.
\end{abstract}

Keywords: Dynamic capillary pressure, fluid flow, tight gas reservoir, two-phase.

\section{INTRODUCTION}

Over the past years, the study of multiphase flow has gained in interest, as it is involved in many field situations, such as unsaturated water flow in the subsurface, remediation of contaminated sites and two phase flow during reservoirs production. Capillarity plays an important role in a multiphase system, as it defines the distribution of the phases and thus the overall behavior of the system. Until today, an empirical relationship between capillary pressure and saturation, obtained by means of laboratory experiments carried out on soil samples, is used to describe capillary pressure. Many studies, especially in China, found that the capillary pressure is a function of the wetting phase pressure and the relationship between capillary pressure and saturation is unique $[1-8]$. The equation is as following:

$p_{c}=p_{n}-p_{w}=f\left(S_{w}\right)$

However, this relationship assumes equilibrium in the distribution of the phases in the porous medium. This assumption is valid in cases where saturation varies slowly, however it may not be appropriate for application in faster processes. In such cases, dynamic effects may have an influence on the system. Different theories have been proposed for the inclusion of dynamic effects in the modeling of multiphase flow. A lot of studies found that the relationship between capillary pressure and saturation is not unique and the dynamic effect of capillary pressure exists in the unbalanced state while it does not exist in the equilibrium state [9-16]. The dynamic capillary pressure refers to the capillary pressure relates to the variation rate of the wetting phase

*Address correspondence to this author at the Research Institute of Petroleum Exploration \& Development of CNPC, Beijing 100083, China; Tel: +86.01083592113; Fax: +86.01083592113;

E-mail: jal@petrochina.com.cn saturation when the wetting-nowetting phase interface fails to reach to the state of equilibrium. The dynamic capillary pressure in unsteady state is larger than that in the equilibrium state or steady state during the process of unsteady experiment. Topp et al. (1967) found that the dynamic effect of capillary pressure (see Fig. 1) and the capillary pressure is bigger than the static capillary pressure under the same saturation when the displacement speed is larger [12].

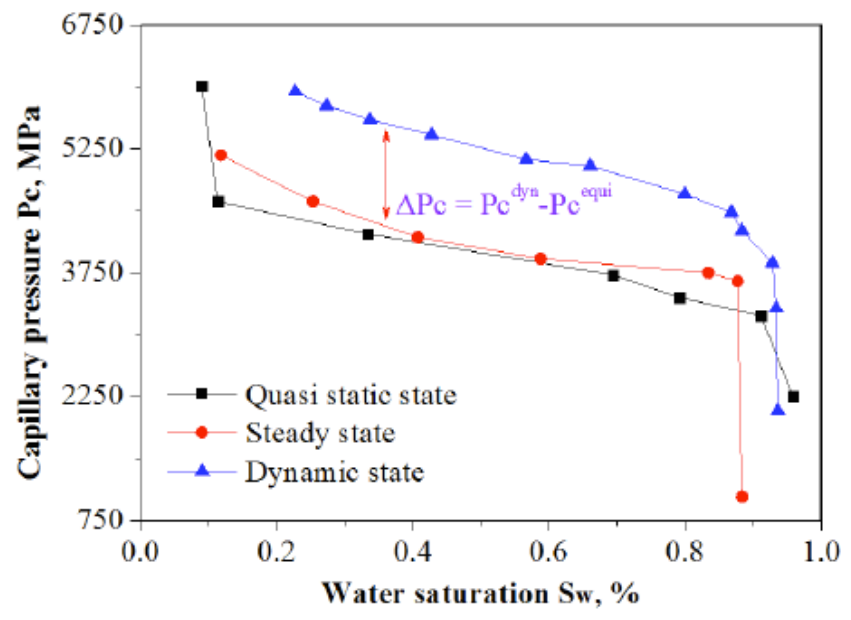

Fig. (1). The dynamic effect of the capillary pressure.

Stauffer (1978) studied the dynamic effect of capillary pressure by displacement experiment. He revealed that the relationship between capillary pressure and saturation is not unique and the transient capillary pressure is greater than quasi static capillary pressure [17]. He also established empirical equations between capillary pressure and saturation [18]. Hassanizadeh et al. (1993) confirmed that the equations proposed by Stauffer are correct [19-22]. The new relationship 
between $p_{c}$ and $S_{w}$ introduces a so-called dynamic capillary pressure, and hypothesizes that the rate of change of saturation is a function of the difference between the dynamic capillary pressure and the static, or equilibrium, capillary pressure. Assuming that a linear relationship holds, one will have,

$p_{c}^{d y n}-p_{c}^{\text {stat }}\left(S_{w}\right)=-\tau_{s} \frac{\partial S_{w}}{\partial t}$

In Equation (2), $p_{c}^{\text {stat }}$ is the static or equilibrium capillary pressure, taken to be the capillary pressure that is traditionally measured in equilibrium pressure cell tests, see for example Stephens (1995); $\tau_{s}$ is a coefficient that we will call the "dynamic coefficient"; and $p_{c}^{d y n}$ is the dynamic capillary pressure, defined as the difference between the volumeaveraged pressure in the nonwetting phase and that in the wetting phase, viz [23, 24].

$p_{c}^{d y n}=p_{n}-p_{w}$

where the angular brackets imply volume averaging. Notice that the averaging procedure introduces a length (and time) scale, The dynamic coefficient may still be a function of saturation as well as fluids and solid properties. Stauffer (1978) has suggested the following scaling of the dynamic coefficient:

$\tau_{s}=\frac{\alpha_{s} \mu_{w} \phi}{K \lambda}\left(\frac{P_{e}}{\rho_{u} g}\right)^{2}$

where, $\alpha$ - constant, which is equal to $0.1 ; \varphi^{-}$porosity, fraction; $\mu_{w}$-viscosity of the wetting phase, $\mathrm{mPa} \cdot \mathrm{s} ; P_{e}, \lambda$-factors of the relationship between capillary pressure and saturation in the Brook-Corey model; $K$-absolute permeability of the wetting phase, $10^{-3} \mathrm{\mu m}^{2} ; \rho_{w}$-density of the wetting phase, $\mathrm{kg} / \mathrm{m}^{3}, g$-gravity acceleration, $\mathrm{m} / \mathrm{s}^{2}$.

In the past work, Helge et al. (2005) consider some of the underlying physical mechanisms that give rise to this socalled dynamic effect. To do this, analyzed a simple bundleof-tubes model that represents the pore space of a porous medium (see Fig. 2). This model is analogous to the model of Bartley and Ruth $(1999,2001)$, who used a bundle-oftubes model to analyze dynamic effects in relative permeability, Bartley and Ruth (2001) also presented initial calculations on dynamic effects on the Pc- S relationship [25].

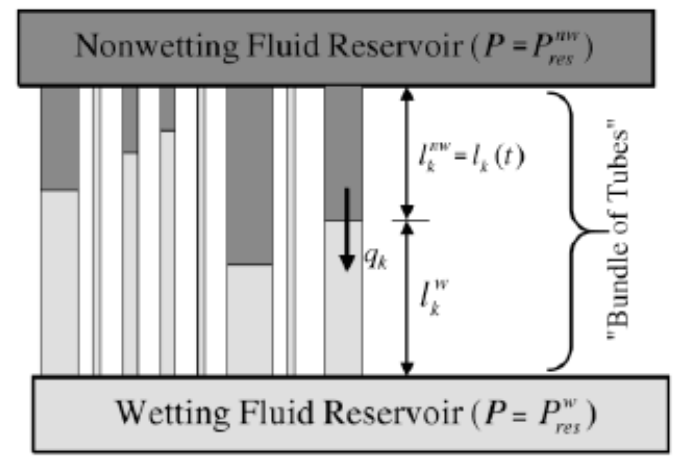

Fig. (2). Bundle-of-tubes model.

Wildenschild et al. (2001) found that the dynamic effect of capillary pressure is obvious in sandstones and the capil- lary pressure will be larger at faster displacement speed. While there is no dynamic effect of capillary pressure in fine grained sandstones [26].

Previous studies show that there is a lack of study about dynamic capillary pressure in tight gas reservoir. Hence, it is necessary to analyze the dynamic capillary pressure through experiments and the influence on tight gas production since the dynamic capillary pressure is obvious in tight formation. In this paper, we aim at studying dynamic capillary pressure and its effects on tight gas reservoir production. First, we study the variation features of seepage resistance by mercury injection experiment. Second, we establish a mathematical model of two-phase flow which considers the dynamic capillary pressure in tight formation. Finally, the dynamic capillary pressure sensitive factors and the effects of dynamic capillary pressure on tight gas production flow are analyzed.

\section{DYNAMIC CAPILLARY PRESSURE}

\subsection{Mercury Injection Experiment}

We analyze the capillary pressure curves under different injection rate by conventional mercury injection experiment with cores of similar physical properties (see Fig. 3). We can see that the faster the mercury injection rate, the greater the capillary pressure will be. The capillary pressure differs not quite when the mercury injection time is $300 s$ and $600 s$ which indicates that the capillary pressure at the mercury injection time of $300 s$ can be approximated for static capillary pressure.

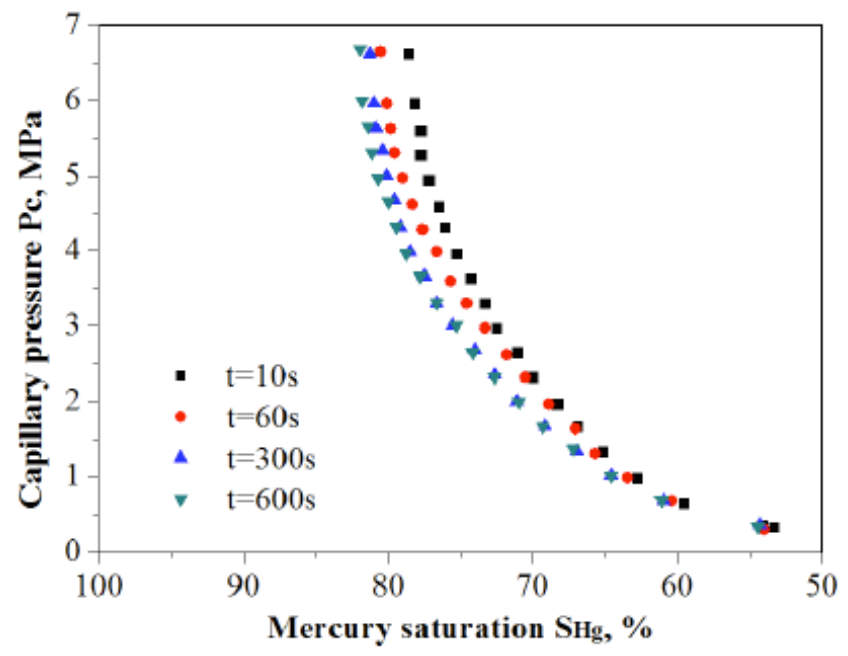

Fig. (3). The capillary pressure curves of different mercury injection rate.

We summarize the relationship between the throats radius and the differentials of dynamic and static capillary pressure based on a number of measurements of cores (see Fig. 4) and can see that the dynamic capillary pressure increases along with the reduction of permeability. The dynamic capillary pressure can be neglected when the permeability is more than $10 \times 10^{-3} \mu^{2}$ while it cannot be neglected when the permeability is less than $1 \times 10^{-3} \mu^{2}$ (ultra-low permeability reservoir). The dynamic capillary pressure is significant (more than $1 \mathrm{MPa}$ ) when the permeability is less than $0.1 \times 10^{-3} \mu^{2}$ (tight gas reservoir). 


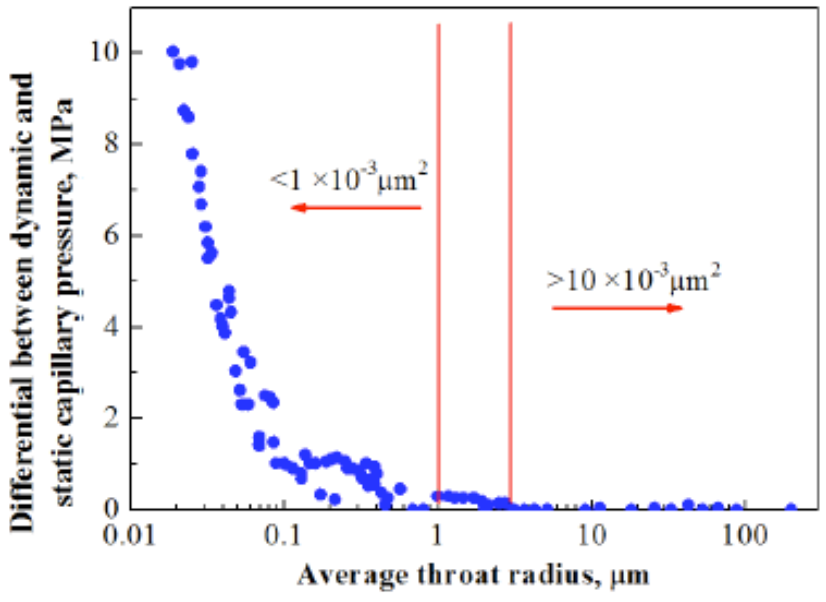

Fig. (4). The dynamic effect of capillary pressure in cores of different permeability.

\subsection{The Factor of Coefficient $\tau$}

First, we calculate the coefficient $\tau$ of ultra-low permeability reservoir (the parameters can be seen in Table 1) which can reach to $10^{11} \sim 10^{13} \mathrm{~kg} /(\mathrm{m} \cdot \mathrm{s})$. While the coefficient $\tau$ calculated by predecessors $[17,19,27,28]$ is only $10^{4} \sim$ $10^{7} \mathrm{~kg} /(\mathrm{m} \cdot \mathrm{s})$, as shown in Table 2 . This indicates that the coefficient $\tau$ is very big in ultra-low permeability reservoir and that is the reason why the dynamic effect of capillary pressure is obvious.

Next, we analyze the dynamic capillary pressure and water saturation distributions under different coefficient $\tau$. Where, the coefficient $\tau$ can be $10^{7}, 10^{8}, 10^{9} \mathrm{~kg} /(\mathrm{m} \cdot \mathrm{s})$, respectively.

In Fig. (5), we see that the capillary pressure is more obvious when the coefficient $\tau$ is bigger. In Fig. (6), the coefficient $\tau$ is $10^{7} \mathrm{~kg} /(\mathrm{m} \cdot \mathrm{s})$ (blue line), $10^{8} \mathrm{~kg} /(\mathrm{m} \cdot \mathrm{s})$ (red line), $10^{9} \mathrm{~kg} /(\mathrm{m} \cdot \mathrm{s})$ (black line), respectively. It indicates that the

Table 1. The parameters used in the calculation of coefficient $\tau$.

\begin{tabular}{|c|c|c|c|c|c|c|c|c|c|}
\hline Sample & $\lambda$ & $\begin{array}{c}\boldsymbol{P}_{e} \\
(\boldsymbol{M P a})\end{array}$ & $\alpha$ & $\begin{array}{c}\mu_{w} \\
(m P a \cdot s)\end{array}$ & $\begin{array}{c}\varphi \\
(\%)\end{array}$ & $\begin{array}{c}K \\
\left(10^{-3} \mu m^{2}\right)\end{array}$ & $\begin{array}{c}\rho_{w} \\
(k g / m 3)\end{array}$ & $\underset{\left(m / s^{2}\right)}{g}$ & $\begin{array}{c}\tau \\
(\mathrm{kg} /(\mathrm{m} \cdot \mathrm{s}))\end{array}$ \\
\hline $3 \#$ & 0.859 & 0.131 & 0.1 & 1.0 & 9.77 & 0.033 & 1000 & 9.8 & $6.10 \mathrm{E}+13$ \\
\hline $4 \#$ & 0.775 & 0.049 & 0.1 & 1.0 & 12.65 & 0.039 & 1000 & 9.8 & $1.03 \mathrm{E}+13$ \\
\hline $5 \#$ & 1.046 & 0.040 & 0.1 & 1.0 & 12.01 & 0.057 & 1000 & 9.8 & $3.42 \mathrm{E}+12$ \\
\hline $6 \#$ & 0.374 & 0.009 & 0.1 & 1.0 & 12.00 & 0.100 & 1000 & 9.8 & $3.14 \mathrm{E}+11$ \\
\hline $7 \#$ & 0.637 & 0.022 & 0.1 & 1.0 & 14.20 & 0.122 & 1000 & 9.8 & $9.52 \mathrm{E}+11$ \\
\hline $8 \#$ & 0.568 & 0.031 & 0.1 & 1.0 & 12.27 & 0.083 & 1000 & 9.8 & $2.60 \mathrm{E}+12$ \\
\hline
\end{tabular}

Table 2. The parameters $\tau$ of core in the experiment of predecessors.

\begin{tabular}{|c|c|c|c|}
\hline References & Rock Type & Experiment Mode & $\boldsymbol{\tau}(\mathbf{k g} / \mathbf{m} . \mathbf{s})$ \\
\hline \hline Topp et al. $(1967)$ & sand & displacement & $5 \times 10^{7}$ \\
\hline Smile et al. $(1971)$ & sand & displacement & $10^{6}$ to $10^{7}$ \\
\hline Elzeftawy and Mansell (1975) & packsand & displacement & $3 \times 10^{4}$ \\
\hline Stauffer (1978) & sand & displacement & $3 \times 10^{4}$ \\
\hline Stauffer (1978) & sand & displacement & $1.5 \times 10^{6}$ to $6 \times 10^{6}$ \\
\hline Wanna-Etyem (1982) & Dune-sand & displacement & $2 \times 10^{6}$ \\
\hline Nutzmann et al. (1994) & sand & displacement & $2 \times 10^{6}$ to $12 \times 10^{6}$ \\
\hline Hollenbeck and Jensen (1998) & sand & displacement & $2 \times 10^{6}$ \\
\hline Kalaydjian (1992) & sand/limestone & imbibition & \\
\hline
\end{tabular}

Table 3. The parameters used in the case.

\begin{tabular}{|c|c|c|c|c|c|c|}
\hline $\boldsymbol{K}\left(10^{-3} \boldsymbol{\mu m}^{2}\right)$ & $\boldsymbol{\rho}$ & $\boldsymbol{q}_{\boldsymbol{w}}(\mathrm{ml} / \mathrm{min})$ & $\boldsymbol{L}(\boldsymbol{m})$ & $\boldsymbol{d}(\boldsymbol{m})$ & $\boldsymbol{\mu}_{o}(\mathrm{mPa} \cdot \mathbf{s})$ & $\boldsymbol{\mu}_{w}(\mathrm{mPa} \cdot \mathbf{s})$ \\
\hline \hline 0.1 & 0.1 & 0.1 & 1 & 0.025 & 2 \\
\hline
\end{tabular}


coefficient $\tau$ is bigger when the reservoir is tighter and the dynamic capillary pressure has a bigger resistance to water so that the dynamic capillary pressure hinders the flitting speed of nonwetting phase.

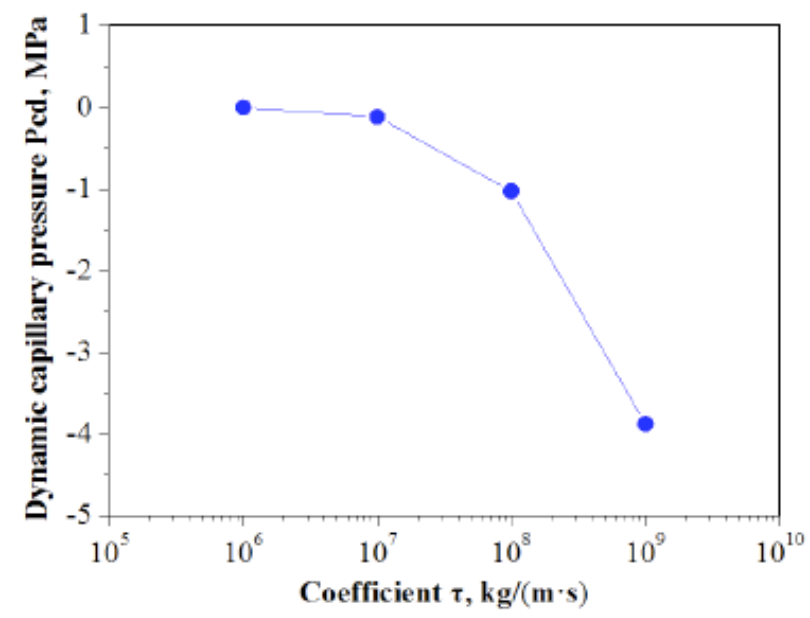

Fig. (5). The dynamic capillary pressure versus the coefficient $\tau$.

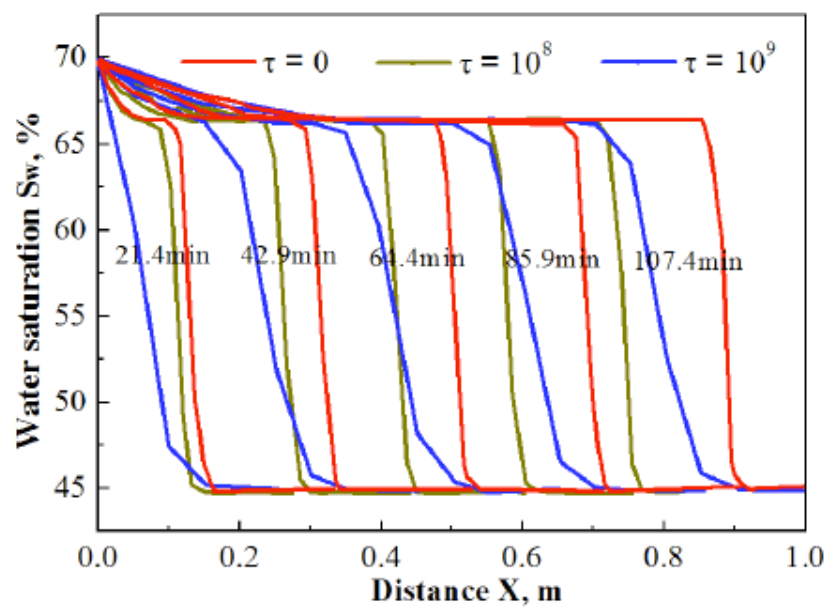

Fig. (6). The water saturation versus the coefficient $\tau$.

\section{THE MATHEMATICAL MODEL}

By previous study, we can see that the dynamic effect of capillary pressure increases the seepage resistance and increases along with the increase of coefficient $\tau$ and the variation rate of water saturation. The dynamic capillary pressure depends on porosity and the absolute permeability of wetting phase which is determined by the microscopic pore structure of cores. The tighter the reservoir is, the more obvious the dynamic capillary pressure will be. So the dynamic capillary pressure needs to be considered when we establish a percolation model of two-phase in tight gas reservoir.

Considering fluid flow to a single well in tight gas reservoir, we assume that (1) the seepage of fluid is isothermal; (2) Darcy (laminar) flow; (3) a porous medium with negligible porosity or permeability changes; (4) no chemical reactions between fluid and solid; and (5) the capillary pressure is variable. Then we can establish a mathematical model of two-phase which considers the dynamic capillary pressure in tight gas reservoir.

\subsection{The Conservation Equation}

$\left\{\begin{array}{l}-\nabla \bullet\left(\rho_{g} V_{g}\right)+q_{g}=\frac{\partial\left(\phi \rho_{g} S_{g}\right)}{\partial t} \\ -\nabla \bullet\left(\rho_{w} V_{w}\right)+q_{w}=\frac{\partial\left(\phi \rho_{w} S_{w}\right)}{\partial t}\end{array}\right.$

\subsection{The Transport Equation}

State equation:

$$
\left\{\begin{array}{l}
C_{g}=-B_{g} \frac{d B_{g}}{d p_{g}}=\frac{1}{p}-\frac{1}{Z} \frac{d Z}{d p} \\
C_{w}=\frac{1}{\rho_{w}} \frac{d \rho_{w}}{d p} \\
C_{f}=\frac{1}{\phi} \frac{d \phi}{d p}
\end{array}\right.
$$

Capillary pressure:

$\left\{\begin{array}{l}p_{c}^{d y n}-p_{c}^{s t a t}\left(S_{w}\right)=-\tau_{s} \frac{\partial S_{w}}{\partial t} \\ p_{c}^{d y n}=p_{n}-p_{w}\end{array}\right.$

Volume factor:

$$
\left\{\begin{array}{l}
B_{g}=\frac{V_{g}}{V_{g s}}=\frac{M / \rho_{g}}{M / \rho_{g s c}}=\frac{\rho_{g s c}}{\rho_{g}} \\
B_{w}=\frac{V_{w}}{V_{w s}}=\frac{M / \rho_{w}}{M / \rho_{w s c}}=\frac{\rho_{w s c}}{\rho_{w}}
\end{array}\right.
$$

Relative permeability:

$\left\{\begin{array}{l}K_{r g}=K_{r g}\left(S_{g}\right) \\ K_{r w}=K_{r w}\left(S_{w}\right)\end{array}\right.$

Density:

$\left\{\begin{array}{l}\rho_{g}=\rho_{g}\left(p_{g}\right) \\ \rho_{w}=\rho_{w}\left(p_{w}\right)\end{array}\right.$

Viscosity:

$\left\{\begin{array}{l}\mu_{g}=\mu_{g}\left(p_{g}\right) \\ \mu_{w}=\mu_{w}\left(p_{w}\right)\end{array}\right.$

\subsection{Definite Condition}

$$
\left\{\begin{array}{l}
\frac{\partial P}{\partial \vec{n}}\left(x, y \in \Gamma_{\text {Dout }}\right)=0 \\
p\left(r_{w}, t\right)=\text { const } \\
\left.r \frac{\partial p(r, t)}{\partial r}\right|_{r_{w}}=\text { const } \\
p(x, y, t=0)=p_{i} \\
S_{\mathrm{g}}(x, y, t=0)=S_{\mathrm{g}}
\end{array}\right.
$$




\section{2D NUMERICAL SIMULATIONS}

\subsection{Governing Equations and Discretized Formulation}

The tight gas reservoir model includes two phases (gas and water) with fluid compressibility and capillary pressure. The conservation equations are nonlinear due to the strong nonlinear character of the relative permeability and dynamic capillary pressure relations, high compressiblity of gas, large density and viscosity difference. According to Eqs. (5) to (10), the governing equations for the tight gas formulation are:

$\frac{\partial}{\partial x}\left(\left(\frac{K_{r g} K_{0}}{B_{g} \mu_{g}}+\frac{K_{r w} K_{0}}{B_{w} \mu_{w}}\right) \frac{\partial p_{g}}{\partial x}\right)+\frac{\partial}{\partial y}\left(\left(\frac{K_{r g} K_{0}}{B_{g} \mu_{g}}+\frac{K_{r w} K_{0}}{B_{w} \mu_{w}}\right) \frac{\partial p_{g}}{\partial y}\right)$

$-\frac{\partial}{\partial x}\left(\frac{K_{r w} K_{0}}{B_{w} \mu_{w}} \frac{\partial p_{c}^{d y n}}{\partial x}\right)-\frac{\partial}{\partial y}\left(\frac{K_{r w} K_{0}}{B_{w} \mu_{w}} \frac{\partial p_{c}^{d y n}}{\partial y}\right)+q=\phi C_{f} \frac{\partial p_{a}}{\partial t}+$

$\phi\left(S_{w} C_{w}+\left(1-S_{w}\right) C_{g}\right) \frac{\partial p_{g}}{\partial t}-S_{w} \phi C_{w} \frac{\partial p_{c}^{d y n}}{\partial t}$

where the underlying fine grid, a cell $(\mathrm{i}, \mathrm{j})$ in a Cartesian grid is shown in (Figs. 7, 8).

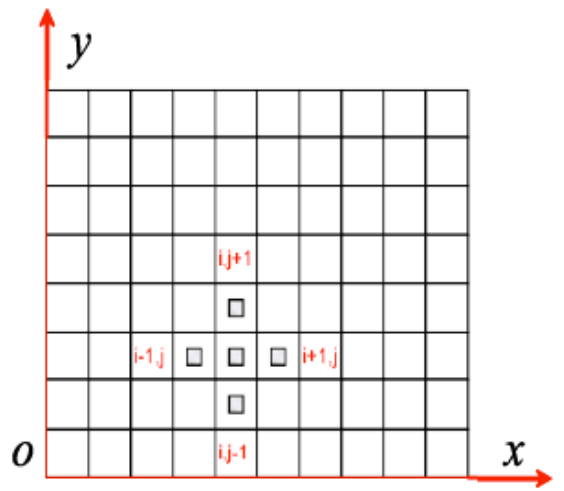

Fig. (7). Discreted grid block.

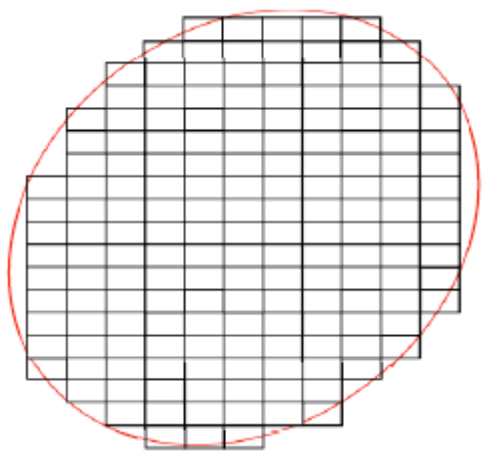

Fig. (8). Surface area of rectangular section.

Divide the formation into a set of rectangular block center cells $\left(\mathrm{Nx}\right.$ in horizontal direction and $N_{y}$ in longitudinal direction). $x=0$ is left boundary, $x_{\text {end }}=N_{x}$ is right boundary, $y=0$ is lower boundary, and $y_{\text {end }}=N_{y}$ is upper boundary. $x_{i}, y_{j}$ is the coordinate of cell $\left(\Delta x_{i}, \Delta y_{j}\right) . x_{i \pm 1 / 2}, y_{j \pm 1 / 2}$ is the coordinate of cell $(i, j), x_{0}, x_{m+1}$ is the mirror of $x_{1}$ and $x_{m}$ respectively. $y_{0}, y_{n+1}$ is the mirror of $y_{1}$ and $y_{n}$, respectively. Assuming a set of cells length is $\Delta x_{1}, \Delta x_{2}, \ldots \Delta x_{m} ; \Delta y_{1}, \Delta y_{2}, \ldots \Delta y_{n}$, the coordinates are obtained;

$$
\begin{aligned}
x_{0} & =-x_{1}, x_{1}=\frac{\Delta x_{1}}{2}, x_{2}=\Delta x_{1}+\frac{\Delta x_{2}}{2}, x_{2} \\
& =\Delta x_{1}+\Delta x_{2}+\frac{\Delta x_{2}}{2}, \cdots, x_{N_{x}}=x_{\text {end }}+\frac{\Delta x_{m}}{2} \\
y_{0} & =-y_{1}, y_{1}=\frac{\Delta y_{1}}{2}, y_{2}=\Delta y_{1}+\frac{\Delta y_{2}}{2}, y_{2} \\
& =\Delta y_{1}+\Delta y_{2}+\frac{\Delta y_{2}}{2}, \cdots, y_{N_{y}}=y_{\text {end }}+\frac{\Delta y_{n}}{2}
\end{aligned}
$$

The following semi-discrete form of the governing equations are obtained:

$$
\begin{aligned}
& \left(\frac{K_{r g} K_{0}}{B_{g} \mu_{g}}+\frac{K_{r w} K_{0}}{B_{w} \mu_{w}}\right)_{i j}^{n} \frac{p_{g i+1, j}^{n+1}-2 p_{g i, j}^{n+1}+p_{g i-1, j}^{n+1}}{\Delta x^{2}}+ \\
& \left(\frac{K_{r g}}{B_{g} \mu_{g}}+\frac{K_{r w} K_{0}}{B_{w} \mu_{w}}\right)_{i j}^{n} \frac{p_{g i, j+1}^{n+1}-2 p_{g i, j}^{n+1}+p_{g i, j-1}^{n+1}}{\Delta y^{2}} \\
& -\left(\frac{K_{r w}}{B_{w} \mu_{w}}\right)_{i j}^{n} \frac{p_{\dot{a}+1, j}^{d y n}-2 p_{\dot{a}, j}^{d y n}+p_{\dot{a}-1, j}^{d y n}-}{\Delta x^{2}} \\
& \left(\frac{K_{r w} K_{0}}{B_{w} \mu_{w}}\right)_{i j}^{n} \frac{p_{i, j+1}^{d y n}-2 p_{i, j}^{d y n}+p_{i, j-1}^{d y n}}{\Delta y^{2}}+q_{i j} \\
& =\phi C_{f} \frac{p_{a i, j}^{n+1}-p_{a i, j}^{n}}{\Delta t}+\phi C_{i} \frac{p_{g i, j}^{n+1}-p_{g i, j}^{n}}{\Delta t}-S_{w} \phi C_{w} \frac{p_{i, j}^{d+t+n}-p_{\dot{i}, j}^{d y n}}{\Delta t}
\end{aligned}
$$

Where, $q_{i j}$ is inner boundary, the equation of the well location is,

$q_{i j}=\frac{Q}{\pi\left(0.14 \sqrt{\Delta y^{2}+\Delta x^{2}}\right)^{2}} \cdot\left(1+\frac{k_{\mathrm{w}}}{\mu_{\mathrm{w}}} \frac{\mu_{\mathrm{g}}}{k_{\mathrm{g}}}\right)$

When not well location, the equation is:

$q_{i j}=0$

Where, the equivalent radius $r_{e} \approx 0.14 \sqrt{\Delta x^{2}+\Delta y^{2}}$, $\Delta x, \Delta y$ is the length of well located cell.

The outer boundary conditions are;

$$
\begin{array}{lc}
p_{0, j}^{n+1}-p_{1, j}^{n+1}=\lambda \Delta x & j=0,1,2, \cdots, N_{y}, N_{y+1} \\
p_{i, 0}^{n+1}-p_{i, 1}^{n+1}=\lambda \Delta y & i=0,1,2, \cdots, N_{x}, N_{x+1} \\
p_{N_{x}, j}^{n+1}-p_{N_{x}+1, j}^{n+1}=\lambda \Delta x & j=0,1,2, \cdots, N_{y}, N_{y+1} \\
p_{i, N y}^{n+1}-p_{i, N y+1}^{n+1}=\lambda \Delta y & i=0,1,2, \cdots, N_{x}, N_{x+1}
\end{array}
$$

\subsection{Parameters}

\subsubsection{Physical Properties}

Table 4 shows basic reservoir properties.

\subsubsection{Relative Permeability and Static Capillary Pressure}

The relative permeability and static capillary pressure used in the $2 \mathrm{D}$ numerical simulation is shown in (Figs. 9, 10). 
Table 4. Basic reservoir parameters.

\begin{tabular}{|c|c|c|c|}
\hline Permeability $(\mathrm{mD})$ & 0.08 & Formation effective thickness $(\mathrm{m})$ & 10 \\
\hline Initial formation pressure (MPa) & 27.6 & Reservoir porosity $(\%)$ & 8.5 \\
\hline Water viscosity $(\mathrm{mPa} \cdot \mathrm{s})$ & 0.46 & Water density $\left(\mathrm{g} / \mathrm{cm}^{3}\right)$ & 0.998 \\
\hline Water volume factor & 1.001 & Gas relative permeability & 0.6735 \\
\hline Water compressibility $\left(10^{-5} / \mathrm{atm}\right)$ & 4.61 & ${\text { Rock compressibility }\left(10^{-4} \mathrm{MPa}^{-1}\right)}_{7.24}^{4}$ \\
\hline$\tau(\mathrm{kg} /(\mathrm{m} . \mathrm{s}))$ & $5.13 \mathrm{E}+12$ & Initial gas saturation $(\%)$ & 42 \\
\hline
\end{tabular}

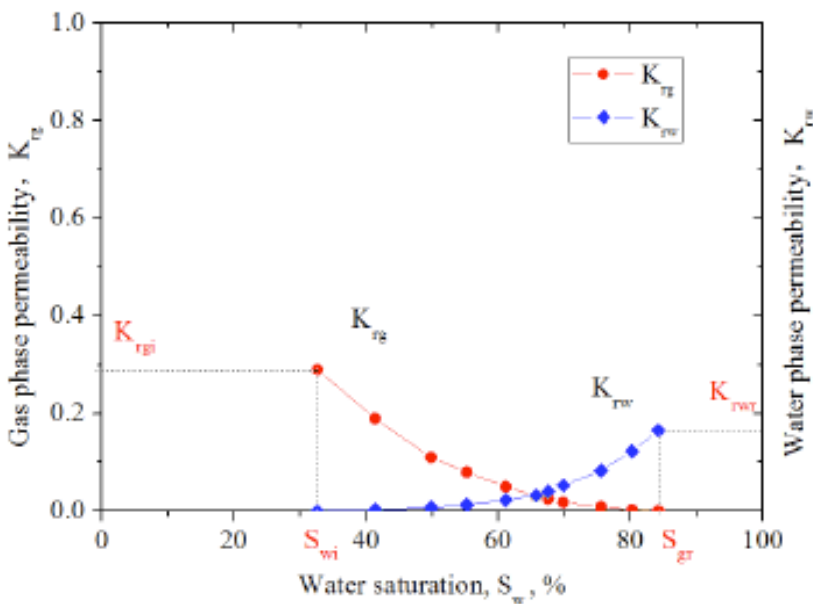

Fig. (9). Gas water relative permeability curve.

\subsubsection{High-pressure Physical Property of Natural Gas}

Table 5 provides the high-pressure physical property of natural gas.

Table 5. High-pressure physical property of natural gas.

\begin{tabular}{|c|c|c|}
\hline Pressure (MPa) & Gas Deviation Factor Z & Viscosity (mpa•s) \\
\hline \hline 0.1 & 0.998905 & 0.0136359 \\
\hline 1 & 0.989495 & 0.0137098 \\
\hline 2 & 0.979637 & 0.0138055 \\
\hline 4 & 0.961941 & 0.014047 \\
\hline 10 & 0.925958 & 0.015231 \\
\hline 12 & 0.919738 & 0.0157916 \\
\hline 16 & 0.915399 & 0.0171559 \\
\hline 18 & 0.916918 & 0.0179471 \\
\hline 20 & 0.92071 & 0.0187941 \\
\hline 24 & 0.933962 & 0.0206155 \\
\hline 26 & 0.942981 & 0.0215677 \\
\hline 28 & 0.95333 & 0.0225342 \\
\hline 30 & 0.964835 & 0.0235069 \\
\hline 32 & 0.977341 & 0.0244794 \\
\hline
\end{tabular}

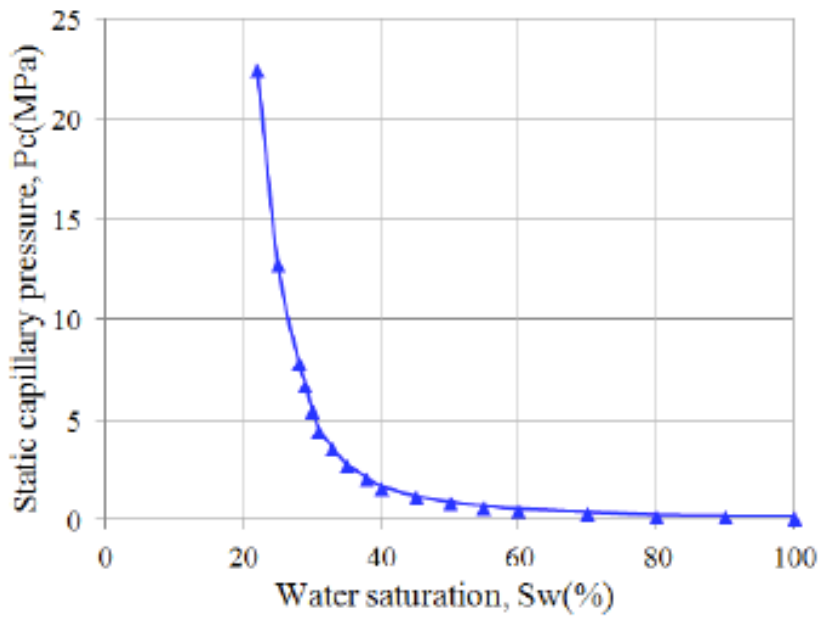

Fig. (10). Capillary pressure curve.

\section{RESULTS AND DISCUSSION}

To illustrate the effects of dynamic capillary pressure on tight gas reservoir production, several synthetic production data have been generated using the above 2D numerical simulation. Assuming 3 scenarios of gas production rates $\left(5000 \mathrm{~m}^{3} / \mathrm{d}, 10000 \mathrm{~m}^{3} / \mathrm{d}\right.$, and $\left.15000 \mathrm{~m}^{3} / \mathrm{d}\right)$, Figs. (11-16) are pressure distributions in reservoir at the end of stable production period considering static capillary pressure and dynamic capillary pressure. It is seen that the pressure in reservoir at the end of stable production period is bigger considering static capillary pressure than that considering dynamic capillary pressure. From the feature of these Figs, degree of pressure decrease is higher due to dynamic capillary pressure increasing pressure depletion.

Figs. $(17,18)$ show the influence of dynamic capillary pressure on stable production period and gas reservoir recovery efficiency. The stable production period of gas reservoir considering static capillary pressure is longer than that considering dynamic capillary pressure. And the gas reservoir recovery efficiency is higher than that considering dynamic capillary pressure. And not only that, when the gas production rate is higher, effects of dynamic capillary pressure on stable production period and gas reservoir recovery efficiency are more obvious.

\section{CONCLUSION}

(1) The dynamic capillary pressure is obvious in ultra-low permeability reservoir, especially in tight gas reservoir. According to Eq. 2, we find the coefficient $\tau$ is $10^{11} \sim$ $10^{13} \mathrm{~kg} /(\mathrm{m} \cdot \mathrm{s})$, which is very bigger than $10^{4} \sim 10^{7} \mathrm{~kg} /(\mathrm{m} \cdot \mathrm{s})$, 


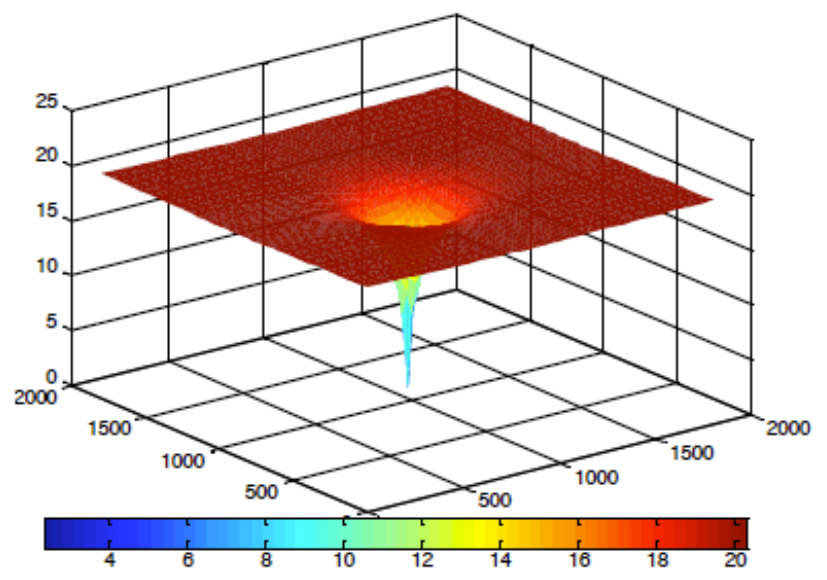

Fig. (11). Pressure distribution in reservoir at the end of stable production period $\left(5000 \mathrm{~m}^{3} / \mathrm{d}\right)$ considering static capillary pressure.

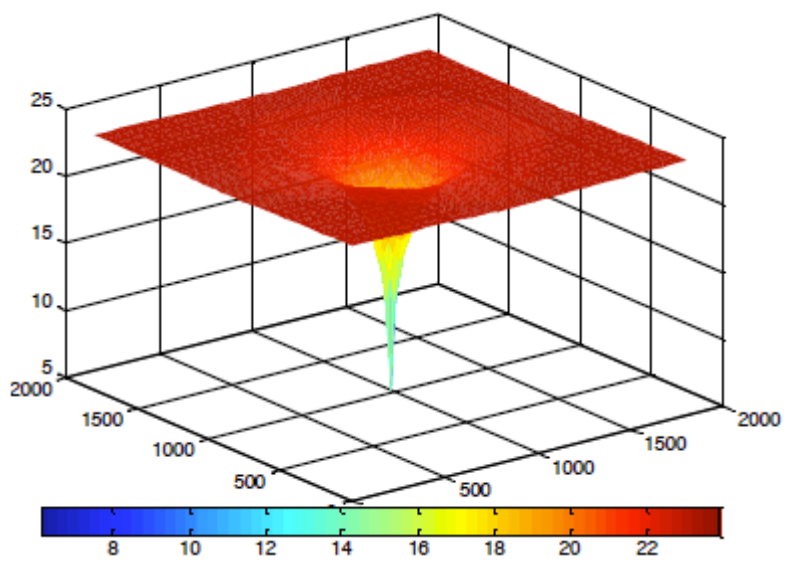

Fig. (13). Pressure distribution in reservoir at the end of stable production period $\left(10000 \mathrm{~m}^{3} / \mathrm{d}\right)$ considering static capillary pressure.

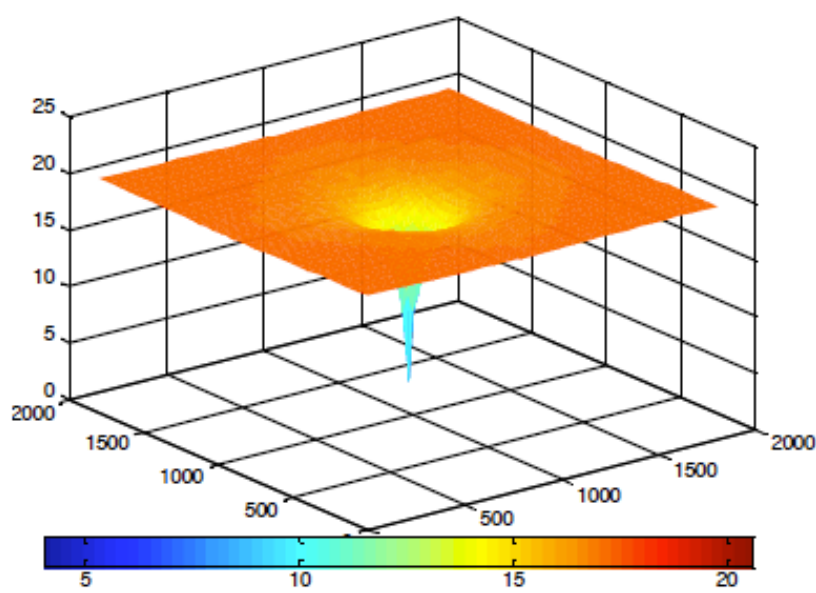

Fig. (15). Pressure distribution in reservoir at the end of stable production period $\left(15000 \mathrm{~m}^{3} / \mathrm{d}\right)$ considering static capillary pressure.

which is calculated by predecessors, when the reservoir is tighter (the permeability is less than $1 \times 10^{-3} \mu^{2}$ ). The coefficient $\tau$ and the variation rate of water saturation influence the dynamic capillary pressure. When the coefficient $\tau$ or the injection rate is bigger, the dynamic effect of capillary pressure will be more obvious.

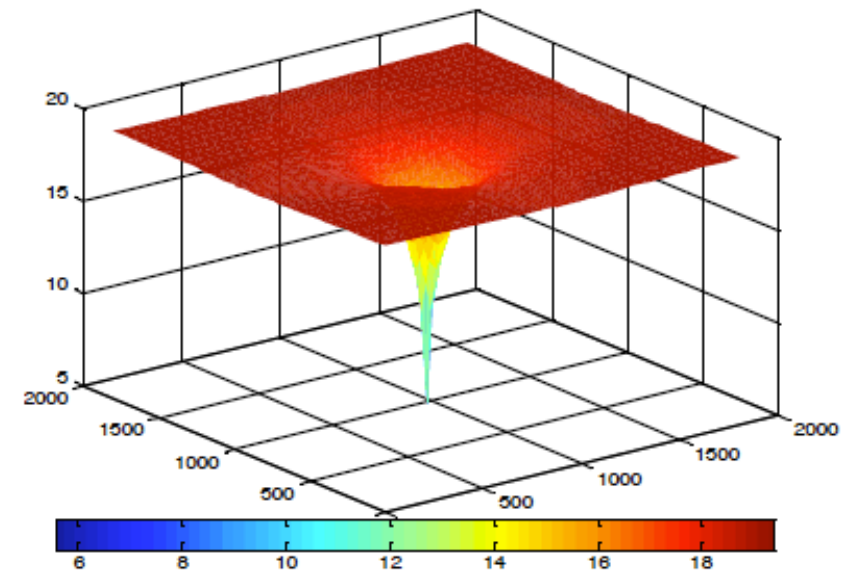

Fig. (12). Pressure distribution in reservoir at the end of stable production period $\left(5000 \mathrm{~m}^{3} / \mathrm{d}\right)$ considering dynamic capillary pressure.

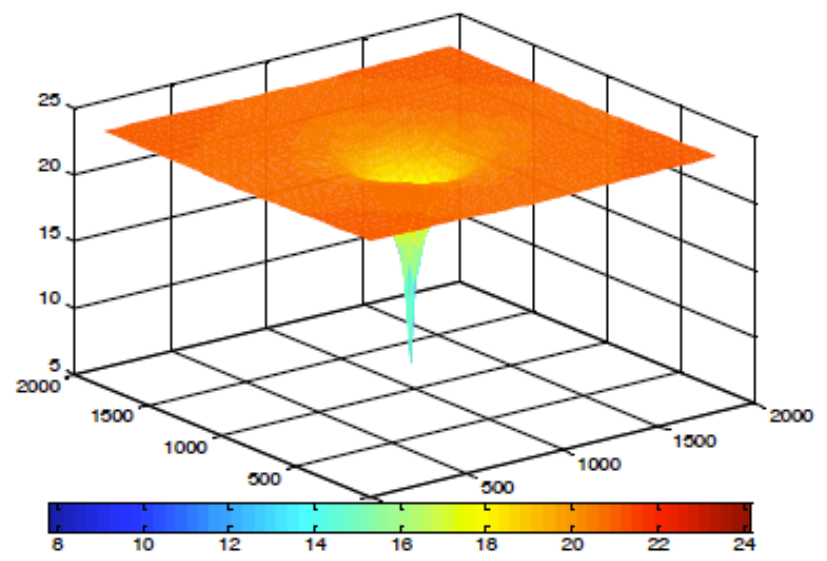

Fig. (14). Pressure distribution in reservoir at the end of stable production period $\left(10000 \mathrm{~m}^{3} / \mathrm{d}\right)$ considering dynamic capillary pressure.

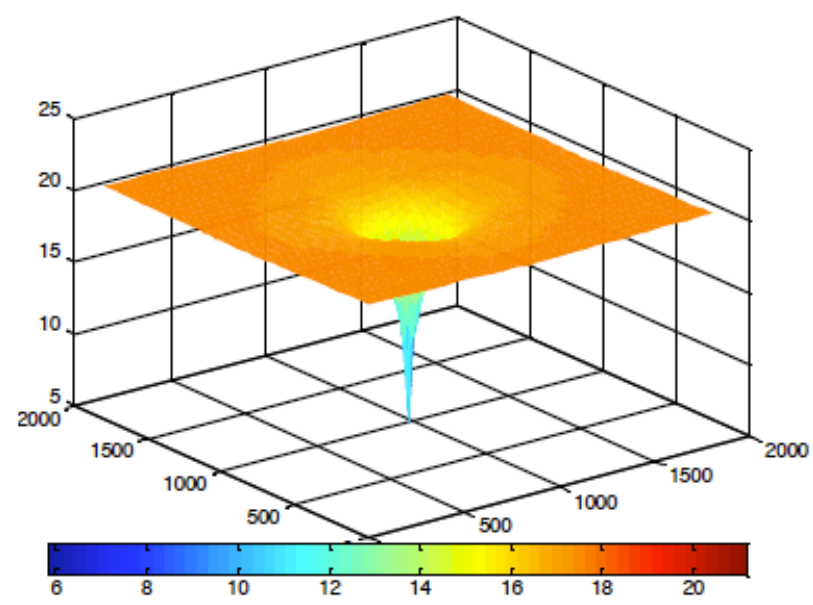

Fig. (16). Pressure distribution in reservoir at the end of stable production period $\left(15000 \mathrm{~m}^{3} / \mathrm{d}\right)$ considering dynamic capillary pressure.

(2) The mathematical model of two-phase flow in tight gas reservoir was established, and the effects of the dynamic capillary pressure on tight gas production were investigated through 2D numerical simulation.

(3) The dynamic capillary pressure makes the pressure depletion more significant, the stable production period 


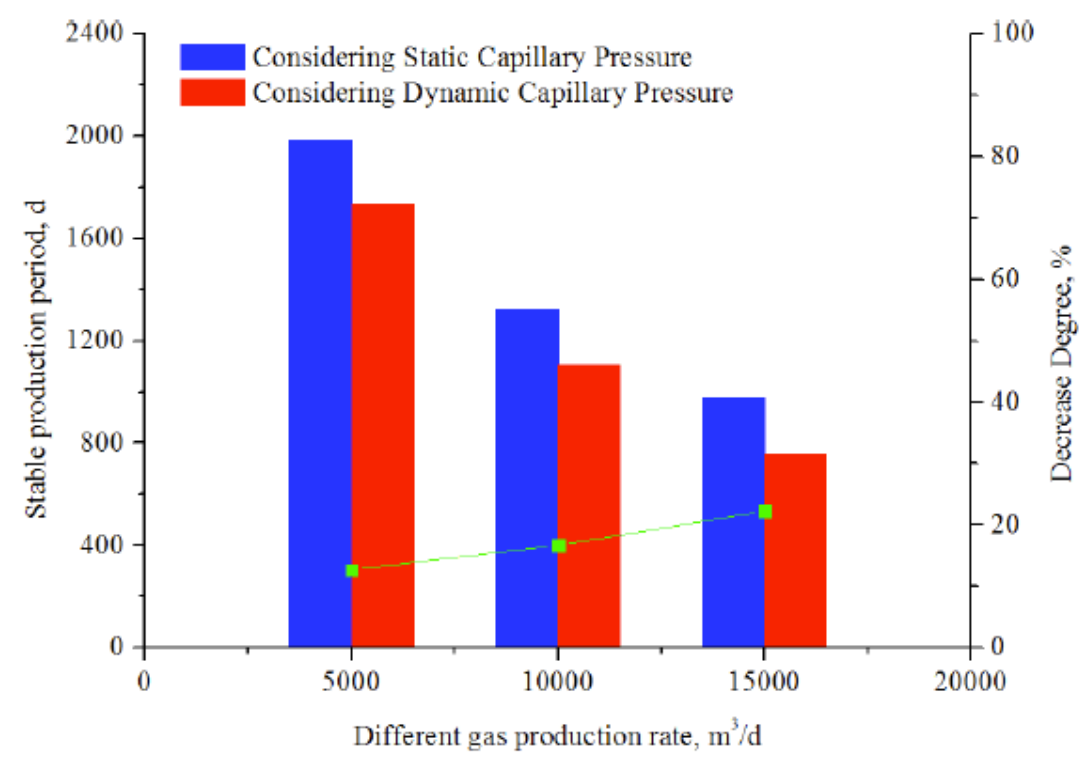

Fig. (17). The stable production period affected by capillary pressure dynamic effect when different daily gas production.

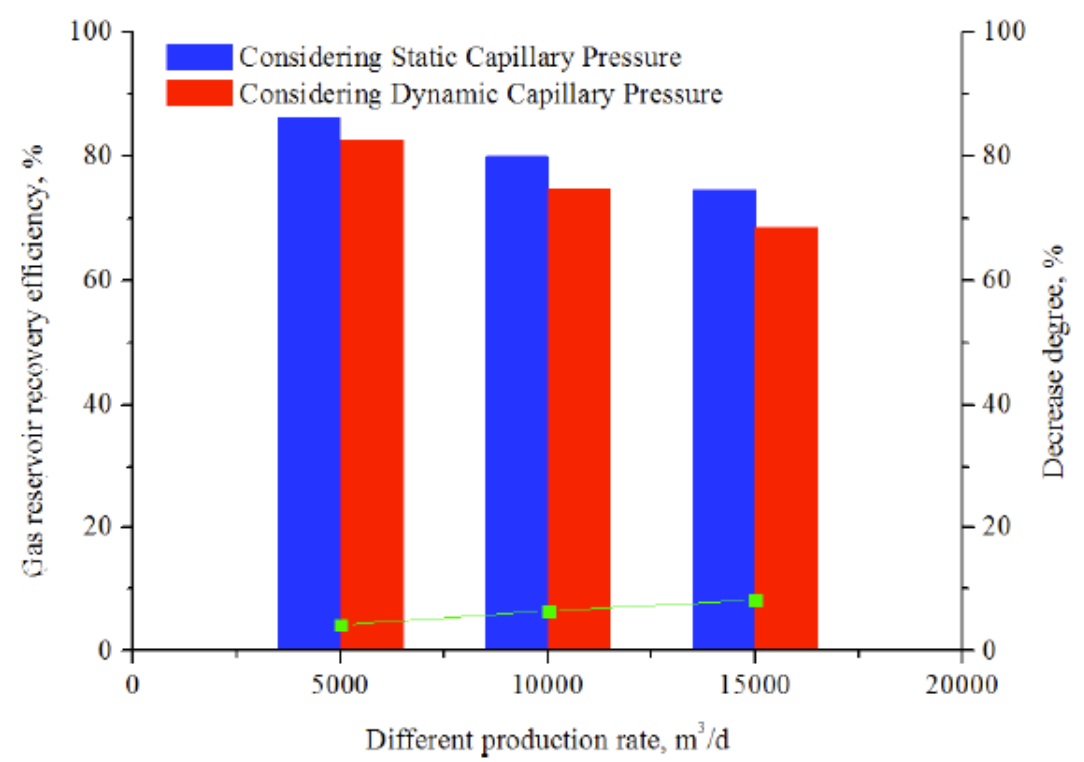

Fig. (18). The gas reservoir recovery efficiency affected by capillary pressure dynamic effect when different daily gas production.

shorter, and the gas reservoir recovery efficiency lower. The larger gas production rate is, the more significant effects of dynamic capillary pressure, due to the great variation rate of water saturation.

This study is of great benefit to finding out the two phase fluid law of tight gas reservoir and the subsequent work of exploitation.

\section{CONFLICT OF INTEREST}

The authors confirm that this article content has no conflict of interest.

\section{ACKNOWLEDGEMENTS}

We thank Benjamin for his valuable work. This article was supported by the Natural Science and Technology Major Project (2011ZX05015) in China.

\section{REFERENCES}

[1] S.D. Hong, Fundamentals of reservoir physics. Beijing: Petroleum Industry Press, 1985.

[2] S.D. Hong, "Drainage-imbibition cycles of wettability, capillary pressure and relative permeability of oil reservoir rock", Journal of the University of Petroleum, China: Edition of Natural Science, vol. 14, no. 6, pp. 107-114, 1990.

[3] H.Q. Sun, S.D. Hong, and S.X. Sun, "Calculation of oil-water relative permeability by using mercury injection data", Journal of the University of Petroleum, China: Edition of Natural Science, vol. 16, no. 1, pp. 41-46, 1992.

[4] S.X. Sun, Y.Y. Guo, and J.H. Qin, "Evaluation of formation damage by capillary pressure data obtained with high pressure semipermeable membrane method", Journal of the University of Petroleum, China: Edition of Natural Science, vol. 14, no. 5, pp. 9-15, 1990.

[5] W. Tang and R.Q. Tang, "Fractal dimensions of mercury-ejection capillary pressure curves in Donghe-1 Oilfield". Acta Petrolei Sinica, vol. 26, no. 5, pp. 90-93, 2005.

[6] X.P. Liu, L. Xiao, and W. Zhang, "Constructing method and application of reservoir capillary pressure curve", Journal of Southwest 
Petroleum University: Science \& Technology Edition, vol. 30, no. 6, pp. 126-130, 2008 .

[7] G.X. Zhao, J.J. Zhu, and L. Guan, "Method of applying capillary pressure data to calculate initial oil saturation", Journal of China University of Petroleum, China: Edition of Natural Science, vol. 32, no. 4, pp. 38-41, 2008.

[8] L. Xiao and W. Zhang, "A new method to construct reservoir capillary pressure curves using NMR log data and its application", $A p$ plied Geophysics: English Edition, vol. 5, no. 2, pp. 92-98, 2008.

[9] D. Kirkham and C. Feng, "Some tests of the diffusion theory and laws of capillary flow in soils", Soil Science, vol. 67, no. 1, pp. 29, 1949.

[10] J. Biggar and A. Sterling, "Some aspects of the kinetics of moisture flow into unsaturated soils", Soil Science Society of America Journal, vol. 24, no. 2, pp. 81, 1959 .

[11] A.M. Elzeftawy, "Hydraulic conductivity calculations for unsaturated steady-state and transient-state flow in sand", Soil Science Society of America Journal, vol. 39, no. 4, pp. 599, 1975.

[12] G. Topp and A. Peters, "Comparison of water content-pressure head data obtained by equilibrium, steady-state, and unsteady-state methods1", Soil Science Society of America Journal, vol. 31, no. 3, pp. $312,1967$.

[13] M. Mirzaei and D. B. Das, "Dynamic effects in capillary pressuresaturations relationships for two-phase flow in 3D porous media:Implications of micro-heterogeneities", Chemical Engineering Science, vol. 62, no. 7, pp. 1927-1947, 2007.

[14] A.Bourgeat and M. Panfilov, "Effective two-phase flow through highly heterogeneous porous media: Capillary nonequilibrium effects", Computational Geosciences, vol. 2, no. 3, pp. 191-215, 1998.

[15] R. Fučík, J. Mikyška, and T. Sakaki, "Numerical study of the effect of dynamic capillary pressure in porous medium", Proceedings of the Czech-Japanese Seminar in applied mathematics. Fukuoka: Kyushu University, pp. 14-30, 2008.

[16] R. Helmig, A. Weiss, and B. I. Wohlmuth, "Dynamic effects in heterogeneous porous media", Computational Geosciences, vol. 11, no. 5, pp. 261-274, 2007.

[17] F. Stauffer, "Time dependence of the relations between capillary pressure, water content and conductivity during drainage of porous media", Proceedings of the International Association of Hydraulic Engineering and Research, pp. 335-352, 1978.

[18] R. Brooks and A. Corey, "Hydraulic properties of porous media", Colorado State University: Fort Collins, 1964.

[19] S. M. Hassanizadeh and W. G. Gray, "Mechanics and thermodynamics of multiphase flow in porous media including interphase boundaries", Advances in Water Resources, vol. 13, no. 4, pp. 169$186,1990$.

[20] S. M. Hassanizadeh and W. G. Gray, "Toward an improved description ofthe physics of two-phase flow", Advances in Water Resources, vol. 16, no. 1, pp. 53-67,1993.

[21] S. M. Hassanizadeh and W. G. Gray, "Thermodynamic basis of capillary pressure in porous media", Water Resources Research, vol. 29 , no. 10 , pp. $3389-3405,1993$.

[22] S. M. Hassanizadeh, M. A. Celia, and H. K. Dahle, "Dynamic effect in the capillary pressure-saturation relationship and its impact on unsaturated flow", Vadose Zone Journal, vol. 1, no. 1, pp. 38-57, 2002.

[23] D. Stephens, Vadose Zone Hydrology. Florida: Lewis Publication, Boca Raton, 1995.

[24] H. K. Dahle, M. A. Celia, and S. M. Hassanizadeh, "Bundle-Tubes model for calculating dynamic effects in the capillary preesure saturation relationship", Transport Porous Media, vol. 58, pp. 5-22, 2005 .

[25] J. T. Bartley and D. W. Ruth, " Relative permeability analysis of tube bundle models, including capillary pressure", Transport Porous Media, vol. 45, pp. 447-480, 2001.

[26] D. Wildenschild, J. Hopmans, and J. Simunek, "Flow rate dependence of soil hydraulic characteristics", Soil Science Society of American Journal, vol. 65, no. 1, pp. 35-48, 2001

[27] J. Wanna, "Static and dynamic water content-pressure head relations of porous media", Fort Collins: Colorado State University, 1982.

[28] G. Nützmann, H. Moser and H. Handke, "Inverse parameter identification of soil hydraulic properties results of a new soil column experiment", Proceedings of Computational Methods in Water Resources, X Heidelberg, Germany, pp. 785-792, 1994.

Received: May 08, 2014

Revised: June 23,2014

Accepted: June 23, 2014

(C) Jia and Lv; Licensee Bentham Open.

This is an open access article licensed under the terms of the Creative Commons Attribution Non-Commercial License (http://creativecommons.org/licenses/by-nc/3.0/) which permits unrestricted, non-commercial use, distribution and reproduction in any medium, provided the work is properly cited. 